\title{
环金属铱配合物在发光电化学池中的应用
}

\author{
周文静 刘志谦王志平胡斯帆梁爱辉* \\ (江西师范大学化学化工学院 功能有机小分子教育部重点实验室 南昌 330022)
}

\begin{abstract}
摘要 与有机电致发光二极管(OLED)相比, 发光电化学池(LEC)的器件结构更加简单, 可以采用高功涵金属作为电极, 因此在照明领域和移动设备终端显示方面具有巨大的应用前景，与其相关的研究与开发越来越受到科学界的重视. 基 于离子型过渡金属配合物的发光电化学池, 由于具有不需要额外添加离子型导电材料和可以充分利用单线态和三线态 激子的优点, 受到业界广泛关注. 与其它离子型过渡金属配合物相比, 离子型铱配合物具有发光效率高、光学稳定性好 以及发光颜色容易调节等优点. 综述了近 10 年环金属铱配合物在发光电化学池中的应用, 重点对离子型铱配合物在发 光电化学池中的应用进行了评述, 并对环金属铱配合物在发光电化学池领域的发展进行了展望.
\end{abstract}

关键词 发光电化学池; 离子型铱配合物; 中性铱配合物

\section{Application of Light-Emitting Electrochemical Cells Based on Cyclometalated Iridium Complexes}

\author{
Zhou, Wenjing Liu, Zhiqian Wang, Zhiping $\mathrm{Hu}$, Sifan Liang, Aihui* \\ (Key Laboratory of Functional Small Organic Molecule, Ministry of Education, College of \\ Chemistry and Chemical Engineering, Jiangxi Normal University, Nanchang 330022)
}

\begin{abstract}
Light-emitting electrochemical cells (LECs), which contain ionic compounds in the light-emitting layer, have attracted considerable interest for their solid-statelighting and next generation display applications. Compared with conventional organic light-emitting diodes (OLEDs), LECs contain simple device architecture (generally only one lightemitting layer), and can use air-stable metals (e.g. Al, $\mathrm{Ag}$ and $\mathrm{Au}$ ) as the cathodes directly. In particular, LECs based on ionic transition metal complexes (iTMCs) have received more attention because of their several advantages over conventional polymer-based LECs. For iTMCs-based LECs, no inorganic salt or ion-conducting polymer is needed because iTMCs are intrinsically ionic. Higher efficiency is expected for iTMCs-based LECs because iTMCs emit efficient phosphorescence at room temperature as they can harvest both singlet and triplet excitons. Compared to other iTMCs, ionic iridium complexes have been widely utilized in optoelectronics, owing to their relevant luminescent properties, such as high emission quantum yields, stability and easy tunability of the emission color. The recent research progress of iridium complexes applied in LECs, including their synthesis, structural characterization and optoelectronic properties is summarized. This review mainly focuses on the development of ionic iridium complex-based LECs with different light-emitting colors and the improvement of device performances. In addition, the future directions of iridium complexes in LECs are also discussed.
\end{abstract}

Keywords light-emitting electrochemical cell; ionic iridium complex; neutral iridium complex

目前报道的发光电化学池主要有两类: 一类是聚合 物基发光电化学池, 另一类是离子型金属配合物基发光 电化学池. 与聚合物基发光电化学池相比, 离子型金属 配合物基发光电化学池有以下特点: (1)因为材料本身含 有导电离子, 所以不需要添加其他的导电材料; (2)因为 有机光电材料受制于 $25 \%$ 单线态激子的影响, 离子型过
渡金属配合物通过自旋耦合作用打破了 $25 \%$ 限制，三线 态激子也被充分利用起来, 获得高的发光效率. 因此, 近年来, 离子型金属配合物基发光电化学池受到众多研 究者的关注.

用于发光电化学池(LEC)的金属配合物主要有钉、 铱、锇 ${ }^{[1]}$ 和铜 ${ }^{[2]}$ 阳离子型配合物. 其中, 钉和铱配合物在

\footnotetext{
* Corresponding author. E-mail: lah14god@163.com

Received December 8, 2018; revised January 16, 2019; published online January 31, 2019.

Project supported by the National Natural Science Foundation of China (Nos. 51763013, 51403088) and the China Postdoctoral Science Foundation (Nos. 2018T110659, 2016M592111).

国家自然科学基金(Nos. 51763013, 51403088)和中国博士后基金(Nos. 2018T110659, 2016M592111)资助项目.
} 
LEC 中得到了广泛应用, 因为其三重激发态寿命相对较 短, 磷光发射效率较高, 且光化学稳定性较好. 迄今为 止, 虽然基于钓配合物的 LEC 最大外量子效率达到了 $6.4 \%{ }^{[3]}$, 但是其发光颜色集中在橙-红光范围内, 难以 达到蓝-绿光的范围. 另外, 离子型钬(II)配合物由于金 属离子价态低, 自身 $\mathrm{d}-\mathrm{d}$ 跃迁能级比较低, 金属 $\mathrm{d}$ 轨道 裂分较小, 因此其激发态容易发生非辐射失活. 与离子 型钓(II)配合物相比, 离子型铱(III)配合物具较高的发光 效率及良好的光学稳定性, 发光颜色容易调节; 其次, 金属与配体间的化学键强度更大, 具有更加优异的发光 性质. 因此, 铱配合物在有机/聚合物发光二极管、化学/ 生物传感等方面具有很好的应用价值, 受到广大研究者 的青睐 ${ }^{[4]}$. 近年来, 诸多具有优异光学性质的铱配合物 被报道, 并在 LECs 中得到了很好地应用, 取得了令人 瞩目的进展 ${ }^{[5]}$.

基于此, 本文简要综述了发光电化学电池的结构和 机理以及近十年铱配合物在发光电化学池中的应用.

\section{1 发光电化学池的基本结构和机理}

\section{1 发光电化学池的基本结构}

LEC 是在发光二极管(LED)的基础上提出来的, 它 是利用发光材料的化学掺杂性质, 实现电化学 $\mathrm{P}$ 型和 $\mathrm{N}$ 型掺杂. LEC 的结构一般主要包括四个部分: 发光材料、 电解质、离子导电体和两个电极(图 1). LEC 结构是由阴 阳两极和中间发光层组成. 与 LED 相比, LEC 的发光层 内含有大量的可自由移动的阴阳离子, 因此具有离子导 电性, 而 LED 的发光层是绝缘的, 无法实现离子导电.

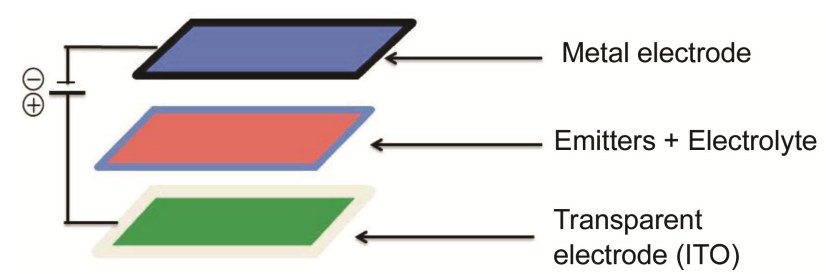

Emitting light

图 1 LEC 的基本结构

Figure 1 Basic structure of LEC

\section{2 发光电化学池的工作机理}

关于 LEC 的工作机理, Pei 等 ${ }^{[6]}$ 认为 LEC 的发光机 理属于电化学掺杂机理(ECD 模型). 他们首次在发光层 中加入电解质, 使其具有良好的离子导电性. 施加一定 电压于两极时，阳极附近的聚合物被氧化实现 $\mathrm{p}$ 型掺杂; 阴极附近的聚合物被还原实现 $\mathrm{n}$ 型掺杂; 在电场作用下 中间的阴阳离子分别向正负两极扩散留下本征聚合物 (i-区)，从而形成 p-i-n 结. 载流子分别从阴阳两极向聚合 物内部扩散, 并在聚合物中复合形成激子, 并辐射发光.

Slinker 等 ${ }^{[7]}$ 在研究离子型过渡金属配合物的发光电 化学池后又提出了另一种机理一一电动力学模型 $(E D$ 模 型). ED 模型认为: 在没有施加电场时, 发光层的最高 占有轨道(HOMO) 和最低空轨道( LUMO) 能级与电极的 费米能级不匹配(图 2a). 此时, 离子成对分布于发光层. 当以一定偏压加载时, 有机层的阴向阳极移动, 而阳离 子向阴极移动, 在两电极表面集聚形成双电子层, 电极 界面的电势被极大地降低，从而有助于电子和空穴注 入, 然后在器件内部的弱电场区复合产生光子(图 2b). 目前，实验数据证实了 $\mathrm{ED}$ 模型，同时也支持 $\mathrm{ECD}$ 模型 的存在. 在过渡金属配合物 LEC 的研究中, 主要偏向于 ED 模型.

(a)

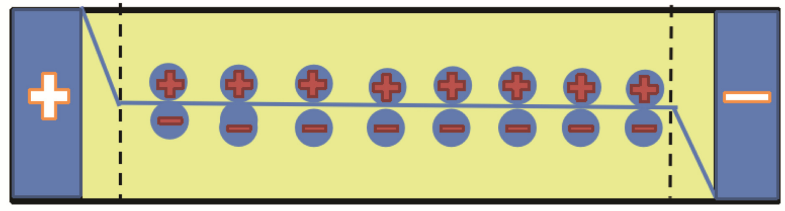

(b)

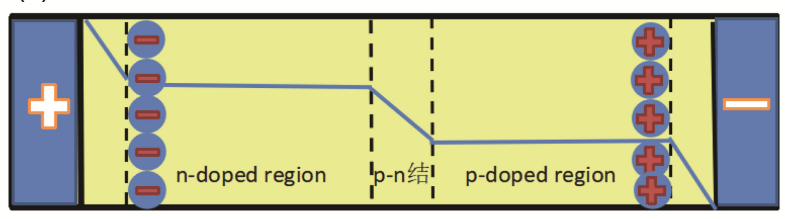

图 2 LEC 的发光机理

Figure 2 Light-emitting mechanism of LEC (a) ECD mechanism; (b) ED mechanism

从发光机理来看, LEC 与 LED 明显不同. 与 LED 相比, LEC 有诸多优点: (1) LEC 可以在电极与有机层界 面处形成欧姆接触，使得载流子的注入无须跨越通常在 LED 中存在的注入势垒, 因此 LEC 对电极的功函不敏 感, 可用于器件的电极可以是稳定的金属(如铝、金、银 等), 即便正负电极使用相同的材料, 也对器件的发光 性能也影响不大; (2)由于 LEC 发光层具有离子导电性, 电阻较低, 所以器件的开启电压相对较低; (3) 器件对发 光层的厚度不敏感, 理论上有机层的厚度与启动电压无 关; (4)器件结构简单, 不需要额外加入电荷注入层, 载 流子注入到发光层材料中是通过界面处的电化学氧化 还原反应, 因此, 电子和空穴的注入比较平衡, 提升了 器件的效率.

但是, LEC 也存在一些问题: LEC 的开启时间依赖 于反离子的迁移率, 但是 LEC 工作时会导致发光层内 反离子的重新分布, 从而导致开启时间比较长; 而且反 离子的体积越大, 重新分布时的移动速度就越慢, LEC 的开启时间就越长. 同时, LEC 的稳定性、寿命及 
亮度与 LED 相比都还有一定差距.

\section{2 离子型铱配合物发光电化学池}

为了获得更高效的发光器件, 科学家们近年来对于 离子型过渡金属铱在 LEC 中应用有了更深入的研究. 阳离子铱配合物作为发光材料与中性铱配合物相比, 具 有以下几个优势: (1)合成条件温和易行, 通常产率较高, 产物纯化比较简单; (2)基于阳离子铱配合物的器件可以 采用惰性金属作为电极, 并得到高效器件; (3)具有良好 的氧化还原可逆性的阳离子配合物, 有助于器件的稳定 性; (4)携带抗衡离子的阳离子铱配合物, 有助于电荷的 传输, 降低器件能耗. 因此离子型铱配合物具有巨大潜 力和市场前景.

通过调控发光颜色可获得用于显示和照明的红、 绿、蓝三基色以及白光发射的发光材料.一般通过最大 发射波长 $\lambda_{\max }$ 和色坐标(CIE) 来确定器件的发光颜色. 2004 年, Slinker 等 ${ }^{[8]}$ 合成了铱配合物 $\mathbf{1}$, 首创性地将其应 用于发光电化学池中, 得到了黄光发射的 LEC. 在实际 应用需求的推动下, 科研人员对铱配合物发光电化学池 进行了深入且系统的研究, 器件发光颜色的调控成为一 个重要的研究内容. 目前, 器件的发光颜色已扩展到整 个可见光区域，并制备出了反映灵敏、高效、寿命长的 白光 LEC.

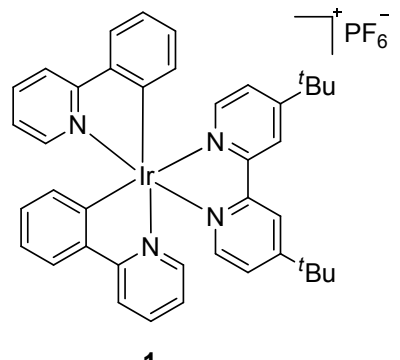

\section{1 红光离子型铱配合物发光电化学池}

基于钓配合物的 LEC 发光通常在橙-红光范围内, 而用其制备的深红光 LEC 效率较差, 目前报道的不多. 铱配合物相比于钓配合物的光致发光量子效率更高, 更 适用于深红光 LEC.

2011 年, Sun 等 ${ }^{[9]}$ 用 2-苯基吡啶为环金属配体，以 $5,5^{\prime}$-二苯基- $2,2^{\prime}$-联吡啶为辅助配体合成了离子型铱配 合物 2, 其 PLQY(苂光量子效率)达到了 $25.6 \%$. 用配合 物 2 为发光层, 高功函的金作为阴极, 制备了单发光层 LEC. 器件具有很好的稳定性, 在 $-4 \mathrm{~V}$ 的偏压下, 半衰 期达到了 $100 \mathrm{~h}$. 研究发现, 在联吡啶的 5,5'位引入大位 阻的基团可以使器件稳定性大大增加.

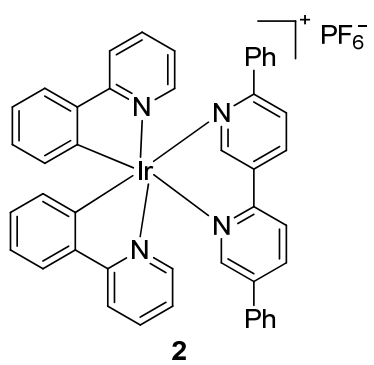

2012 年, Chen 等 ${ }^{[10]}$ 合成了对离子为钠离子的离子 型铱配合物 3 和 4 . 由于铱配合物 3 和 4 的溶解性较差, 且配合物 3 有较高的 LUMO 能级, 电子难以注入 LUMO 能级，因此含有配合物 3 的 LEC 没有发光; 含有 配合物 4 的 LEC, 最大亮度为 $1.51 \mathrm{~cd} \cdot \mathrm{m}^{-2}$, 外量子效率 (EQE) 仅为 $0.02 \%$. 为了改善其溶解性, Chen 等将 18 -冠6 加入配合物 $\mathbf{4}$ 的溶液中, 形成了结构 $\mathbf{5}$, 改善了配合物 的溶解性, 提高了发光层薄膜的质量, 其器件的最大亮 度达到了 $69 \mathrm{~cd} \cdot \mathrm{m}^{-2}, \mathrm{EQE}$ 为 $1.38 \%$.

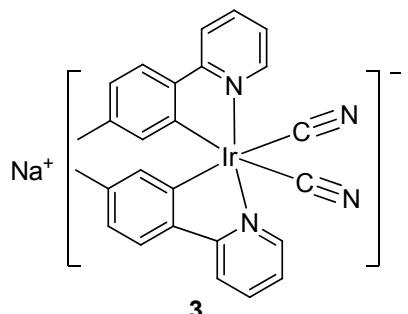

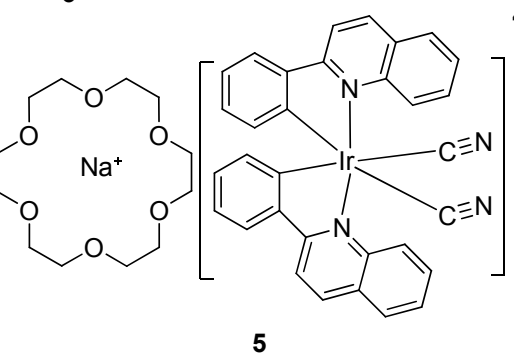

2013 年, Zhang 等 ${ }^{[11]}$ 以苯基吡啶为环金属配体和 1,3,4-噁二唑基吡啶衍生物为辅助配体合成了配合物 $\mathbf{6}$, 其最大发射峰为 $616 \mathrm{~nm}, \mathrm{EQE}$ 高达 $10 \%$ 以上，在 $10 \mathrm{~V}$ 电 压下最大亮度为 $8528 \mathrm{~cd} \cdot \mathrm{m}^{-2}$. 和其它类似的配合物相 比, 配合物 6 具有较高的效率, 这是因为其辅助配体上

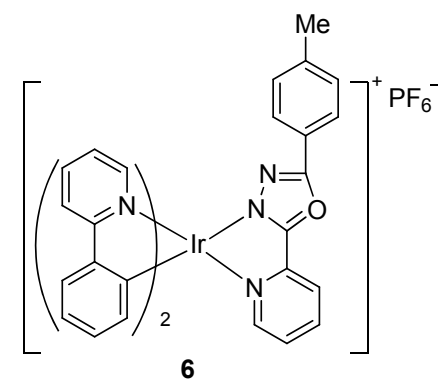


含有单个 1,3,4-噁二唑, 减少了金属-配体的电荷转移淬 灭. 同时配合物 6 在薄膜状态下具有更短的激发态寿命.

$\mathrm{Hu}$ 等 ${ }^{[12]}$ 合成了离子型铱配合物 $7 \mathbf{a}$ 和 $7 \mathbf{b}$, 以 $7 \mathbf{a}$ 为 主体, 以 $7 \mathbf{b}$ 为客体制备了主客体型红光 $\mathrm{LEC}$, 其最大 亮度为 $8.4 \mathrm{~cd} \cdot \mathrm{m}^{-2}$, 外量子效率为 $3.5 \%$, 最大电流效率 为 $3.4 \mathrm{~cd} \cdot \mathrm{A}^{-1}$. 研究表明将客体分子分散到主体基质中 可以极大地抑制发光层中客体分子的自淬灭, 可以很大 程度地提高器件的效率.
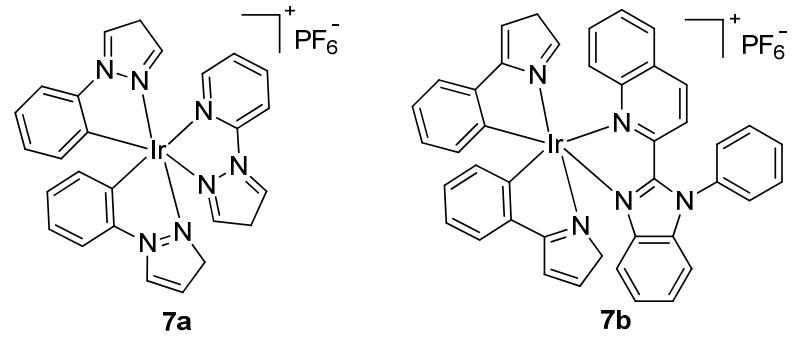

2017 年, Ertl 等 ${ }^{[13]}$ 合成了一系列以苯基吡啶为主配 体, 以苯并噻唑衍生物为辅助配体的离子铱配合物 8 10, 它们的发射峰分别为 644,636 和 $645 \mathrm{~nm}$, PLQY 分 别为 $7.7 \%, 14 \%$ 和 $6.5 \%$. 以配合物 $8 \sim 10$ 为发光层得到 了特别稳定的 LEC 器件, 其 CIE 分别是 $(0.62,0.36)$, $(0.62,0.36)$ 和 $(0.64,0.35)$, 器件的寿命分别超过了 1000 , 6000 和 $4000 \mathrm{~h}$. 密度泛函计算说明通过化学方法改变苯 并噻唑上的取代基只影响配合物的 LUMO 能级, 进而 影响配合物的 HOMO-LUMO 能隙.

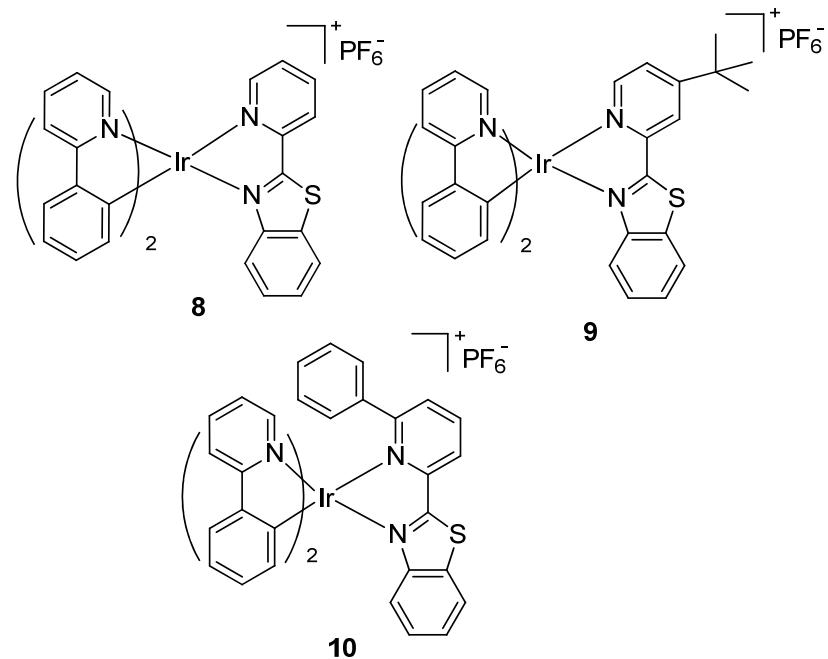

Matteucci 等 ${ }^{[14]}$ 合成了含有双四唑配体的离子型铱 配合物 11, 双四唑配体具有优良的螯合性质, 两个四唑 盐之间仅具有亚甲基桥连接, 可以更好地与金属中心配 位, 而不会导致键角的扭曲和结构应力的产生, 从而改 善了配合物的稳定性. 以配合物 11 为发光层制作的 LEC 的最大发射波长为 $666 \mathrm{~nm}$, PLQY 达到了 $83 \%$.<smiles>Cc1nc2ccccc2nc1-n1nnnc1Cc1nnnn1Cc1ccccc1</smiles>

Martínez-Alonso 等 ${ }^{[15]}$ 合成了吡啶基苯并咪唑为辅 助配体的橙红光离子型铱配合物 12 , 含该配合物的 LEC 的最大发射峰为 $590 \mathrm{~nm}$, 最大亮度为 $904 \mathrm{~cd} \bullet \mathrm{m}^{-2}$, 电流效率为 $9.15 \mathrm{~cd} \cdot \mathrm{A}^{-1}$, 寿命达到了 $2500 \mathrm{~h}$. 由于配合 物 12 中的咪唑上连有甲基, 起到了保护 $\mathrm{N}-\mathrm{H}$ 键的作 用，从而使得器件的发光性能更加稳定.<smiles></smiles>

2017 年, Namanga 等 ${ }^{[16]}$ 用苯并喹啉为主配体和 2,2'联喹啉为辅助配体合成了新型阳离子铱配合物 13. 含 有该配合物的 LEC 呈现深红色发射，最大发射波长为 $662 \mathrm{~nm}$, 亮度为 $33.65 \mathrm{~cd} \bullet \mathrm{m}^{-2}$, 电流效率为 $0.33 \mathrm{~cd} \bullet \mathrm{A}^{-1}$, 功率效率为 $0.2 \mathrm{~lm} \cdot \mathrm{W}^{-1}$. 更为重要的是, 其器件的寿命 达到了 $280 \mathrm{~h}$, 这可能是由于配合物的环金属配体采用 了刚性的苯并喹啉, 减少了分子的振动, 增加了配合物 的稳定性.

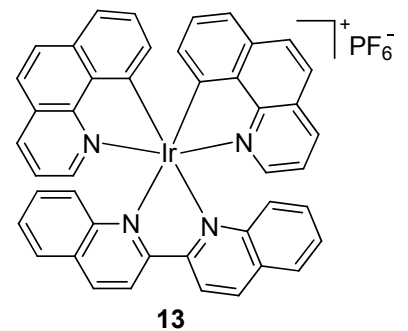

2018 年, Yeonah 等 ${ }^{[17]}$ 以化合物 14 为辅助配体, 2-苯 基吡啶和 2-苯基异喹啉为环金属配体合成了配合物 15 和 16. 配合物 16 的环金属配体共轭长度更长, 使得其 HOMO 轨道能级升高, 而 LUMO 轨道能级不变, 因此 配合物 16 比配合物 15 的能量间隙更窄，发射峰发生红 移. 配合物 15 发橙红色光, 其最大发射峰在 $618 \mathrm{~nm}$, $\mathrm{CIE}$ 坐标为 $(0.59,0.36)$, 最大亮度为 $808 \mathrm{~cd} \cdot \mathrm{m}^{-2}$, 电流效 率为 $0.73 \mathrm{~cd} \cdot \mathrm{A}^{-1}$. 与配合物 15 相比, 配合物 16 的最大 发射峰发生红移, 为 $692 \mathrm{~nm}, \mathrm{CIE}$ 坐标为 $(0.56,0.28)$, 最 大亮度为 $525 \mathrm{~cd} \cdot \mathrm{m}^{-2}$, 电流效率为 $0.20 \mathrm{~cd} \cdot \mathrm{A}^{-1}$. 
<smiles>Cc1ccc(-n2c(-c3ccc4ccccc4n3)nc3c4ccccc4c4ccccc4c32)cc1</smiles><smiles></smiles><smiles></smiles>

15

\section{2 黄光离子型铱配合物发光电化学池}

2011 年 $\mathrm{Xu}$ 等 ${ }^{[18]}$ 分别将 $\mathrm{p}$ 型咔唑基团和 $\mathrm{n}$ 型二(三 甲基苯基)喼基团引入到环金属配体研发了铱配合物 17 和 18, 并制备了发光电化学池, 它们的最大发射峰分别

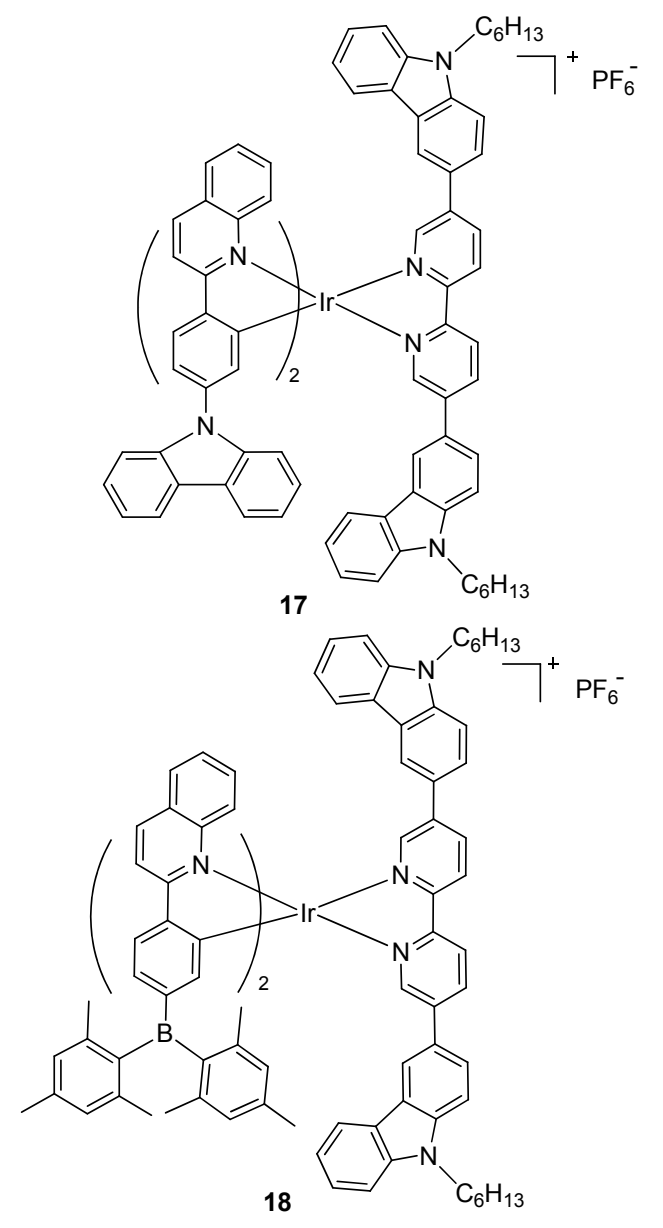

为 559 和 $583 \mathrm{~nm}$, 最大亮度分别为 8.4 和 $31.4 \mathrm{~cd} \cdot \mathrm{m}^{-2}$, $\mathrm{EQE}$ 分别为 $0.14 \%$ 和 $0.13 \%$. 与配合物 17 的发光电化学 池相比，配合物 $\mathbf{1 8}$ 中的二(三甲基苯基)硼基团可以增加 环金属配体的共轭长度，提高磷光量子效率. 此外，大 体积的二(三甲基苯基)硼基团可防止薄膜结构中的分子 聚集，有利于改善器件性能.

2012 年, Kessler 等 ${ }^{[19]}$ 合成了一系列新型的离子型 铱配合物, 它们都是用吡啶一卡宾替代传统的联吡啶作 为辅助配体. 其中配合物的 19 的最大发射峰为 $584 \mathrm{~nm}$, 最大亮度为 $1070 \mathrm{~cd} \cdot \mathrm{m}^{-2}$, 电流效率达到了 $4.7 \mathrm{~cd} \bullet \mathrm{A}^{-1}$. 尽管这些铱配合物在溶液中光致发光量子产率相对较 低, 但是将它们应用于发光电化学电池时, 其发光波长 可以覆盖从蓝绿光到橙光区域.

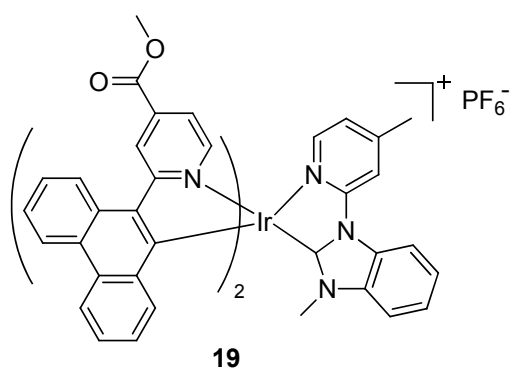

2013 年, Sunesh 等 ${ }^{[20]}$ 以 5-甲基-1,10-菲咯啉为辅助 配体，分别以 2,4-二氟苯基吡啶和苯基吡唑为环金属配 体合成了离子型铱配合物 20 和 21 . 配合物 20 的最大发 射峰位于 $513 \mathrm{~nm}, \mathrm{CIE}$ 坐标为 $(0.25,0.58)$, 最大亮度为 $2430 \mathrm{~cd} \cdot \mathrm{m}^{-2}$. 配合物 21 的最大发射峰位于 $559 \mathrm{~nm}$, 色 坐标为 $(0.42,0.54)$, 最大亮度为 $1549 \mathrm{~cd} \cdot \mathrm{m}^{-2}$. 与非氟化 配体相比，环金属配体上的吸电子基团氟原子的存在使 得配合物的 HOMO 能级更稳定，因此配合物的最大发 射峰发生了蓝移.

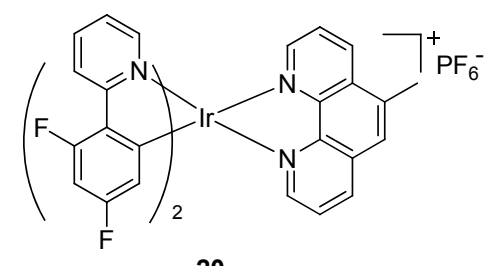

20

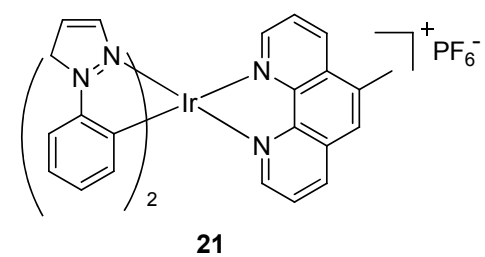

2015 年, Sunesh 等 ${ }^{[21]}$ 以苯并吡唑为环金属配体, 以 吡啶基苯并咪唑为辅助配体合成了阳离子铱配合物 22. 配合物 22 的最大发射峰为 $549 \mathrm{~nm}, \mathrm{CIE}$ 坐标为( 0.41 , 
0.56). 以配合物 $\mathbf{2 2}$ 为发光层的 LEC 的最大亮度为 1492 $\mathrm{cd} \cdot \mathrm{m}^{-2}$, 并且器件即使在 $12 \mathrm{~V}$ 的高电压下也表现出良 好的稳定性. 但是, 由于铱配合物上存在活性的 $\mathrm{N}-\mathrm{H}$ 基团，这会使得分子间相互作用增强，因而会对 LEC 的 电致发光性能产生负面影响.

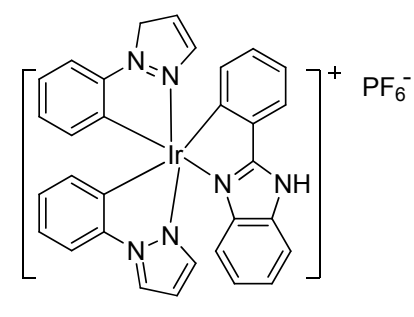

22

2016 年, Zeng 等 ${ }^{[22]}$ 用吡啶基三唑衍生物为辅助配 体开发了黄光离子型铱配合物 23 和蓝色配合物 $\mathbf{2 4}$. 配 合物 24 的最大发射峰为 $499 \mathrm{~nm}$, 色坐标分别为 $(0.26$, $0.48)$, 最大电流效率为 $31.6 \mathrm{~cd} \cdot \mathrm{A}^{-1}$. 配合物 $\mathbf{2 3}$ 的最大发 射峰在 $570 \mathrm{~nm}$, 色坐标分别为 $(0.51,0.47)$, 最大电流效 率为 $40.6 \mathrm{~cd} \cdot \mathrm{A}^{-1}$. 特别重要的是将这两个配合物应用于 大面积可溶液加工 LEC 中器件性能仍然很好, 基于配 合物 23 和 24 的 4 英寸 LEC 的最大电流效率分别为 25.4 和 $23.4 \mathrm{~cd} \bullet \mathrm{A}^{-1}$.

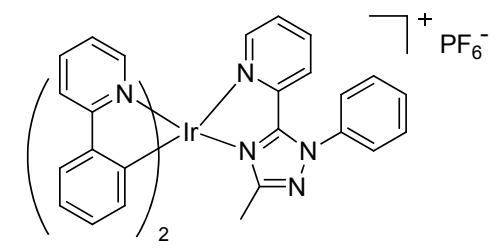

23

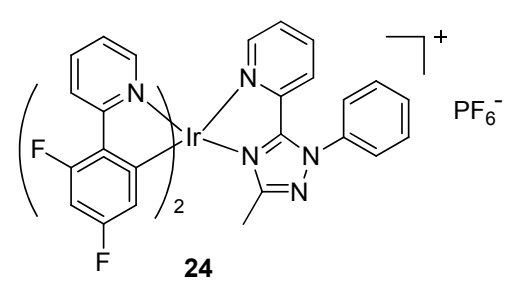

Jeon 等 ${ }^{[23]}$ 用 2-(4-甲基-2-吡啶基)-苯并咪唑作为辅 助配体, 用 2-苯基吡啶和 2-(4-溴苯基)苯并噻唑为环金 属配体, 分别合成了阳离子铱络合物 25 和 $\mathbf{2 6}$. 以配合 物 25 和 26 为发光层的 LEC 分别发射黄光 $(553 \mathrm{~nm}$ ) 和橙

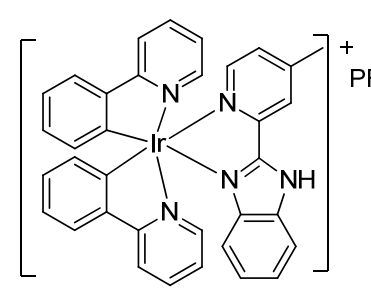

25

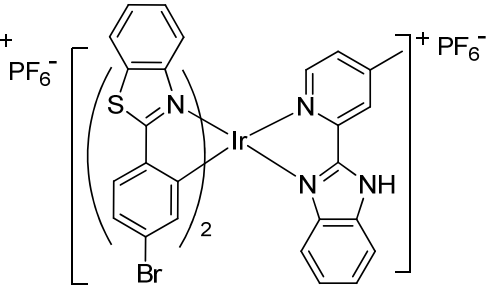

26
光 $(600 \mathrm{~nm})$, 色坐标分别为 $(0.47,0.49)$ 和 $(0.33,0.53)$, 最 大亮度分别为 3636 和 $2315 \mathrm{~cd} \cdot \mathrm{m}^{-2}$, 电流效率分别为 0.35 和 $0.32 \mathrm{~cd} \cdot \mathrm{A}^{-1}$.

2017 年, Jo 等 ${ }^{[24]}$ 合成了两种以菲并咪唑为辅助配体 的阳离子铱配合物 27 和 28 . 菲并咪唑具有优异的光物 理性质，热稳定性和平衡的电荷传输能力. 同时将庞大 的四苯基菲并咪唑作为辅助配体，可以有效减少铱配合 物之间的分子间相互作用, 从而提高了器件的性能. 配 合物 27 和 28 均发射黄色光, 最大发射峰分别在 540 和 $561 \mathrm{~nm}$ 处, CIE 坐标分别为 $(0.46,0.52)$ 和 $(0.49,0.50)$, 最 大亮度分别为 509 和 $826 \mathrm{~cd} \cdot \mathrm{m}^{-2}$, 最大电流效率分别为 0.56 和 $0.26 \mathrm{~cd} \cdot \mathrm{A}^{-1}$.

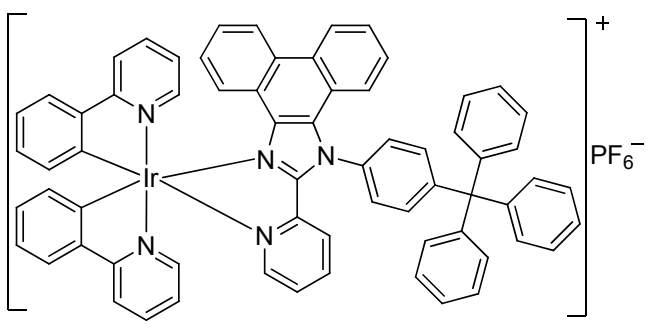

27<smiles></smiles>

28

\section{3 蓝绿光离子型铱配合物发光电化学池}

随着 LEC 的不断研究和发展, 要实现其在显示和 固态照明等方面的应用，最大的挑战与瓶颈就是开发高 效的蓝光 LEC. 蓝光在三基色(红、绿、蓝)中是非常重 要的, 是实现白光必不可少的组成部分. 但是, 目前开 发的蓝光离子型铱配合物还比较少. 近来, 蓝绿光 LEC 的研究成为了热点. 为了使光谱蓝移, 可以通过在配体 上引入功能基团来增大最高占有轨道( HOMO)和最低未 占有轨道(LUMO)的能级差. 通常可以在环金属配体的 苯环上引入吸电子基团, 降低铱配合物的 HOMO 能级; 或者在辅助配体上引入给电子基团, 升高铱配合物的 LUMO 能级, 从而加大 HOMO-LUMO 能隙, 实现发射 波长的蓝移.

基于在配合物的辅助配体中引入给电子的氮原子, 进而提高铱配合物的 LUMO 能级, 获得蓝光离子型铱 配合物的设计思想. Cola 等 ${ }^{[25]}$ 合成了一系列含三唑类配 体的铱配合物 29a 29f, 由于三唑类配体的 LUMO 能 
级比联吡啶类或邻菲罗啉类配体的 LUMO 能级高, 因 此它们的发射在蓝绿光范围. 以这些铱配合物为发光层 的 LEC 达到最大亮度所用的时间为 $120 \sim 860 \mathrm{~s}$, 最大亮 度为 $14.5 \sim 44.9 \mathrm{~cd} \cdot \mathrm{m}^{-2}$. 随后, 他们 ${ }^{[26]}$ 把双咪唑盐 $\mathrm{N}$-杂 环卡宾作为辅助配体引入到离子型铱配合物中，合成了 一系列蓝色发光的铱离子配合物 $30 \mathrm{a} \sim 30 \mathrm{~d}$, 最大发射 峰分别是 $488,488,456$ 和 $456 \mathrm{~nm}$, 最大亮度分别为 21.6 , $25.7,24.0$ 和 $13.4 \mathrm{~cd} \bullet \mathrm{m}^{-2}, \mathrm{CIE}$ 分别为 $(0.27,0.43),(0.27$, $0.43),(0.20,0.34)$ 和 $(0.22,0.38)$. 三氟甲磺酸四丁基铵用 作电解质时, 可以实现较深的蓝色发光和短的反应时 间.
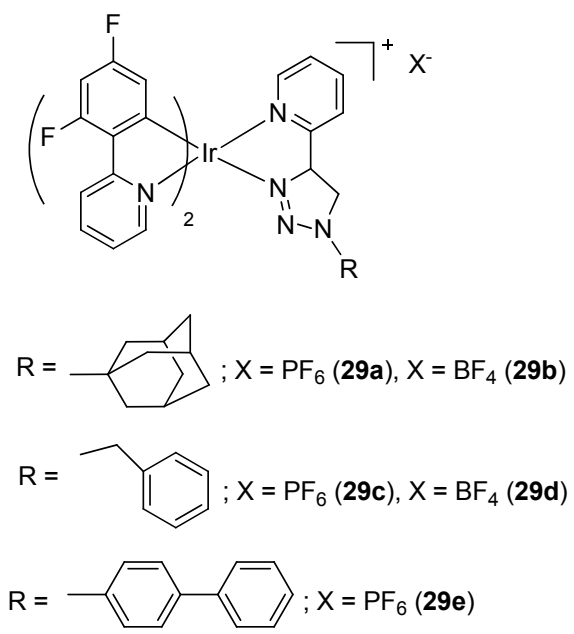

$\mathrm{R}=\square ; \mathrm{X}=\mathrm{BF}_{4}(29 \mathrm{f})$

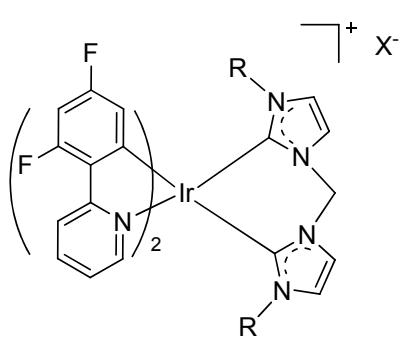

$\mathrm{R}=\mathrm{CH}_{3}, \mathrm{X}=\mathrm{PF}_{6}(\mathbf{3 0 a})$

$\mathrm{R}=\mathrm{CH}_{3}, \mathrm{X}=\mathrm{BF}_{4}(\mathbf{3 0 b})$

$\mathrm{R}=\mathrm{C}_{4} \mathrm{H}_{9}, \mathrm{X}=\mathrm{PF}_{6}(30 \mathrm{c})$

$\mathrm{R}=\mathrm{C}_{4} \mathrm{H}_{9}, \mathrm{X}=\mathrm{BF}_{4}(\mathbf{3 0 d})$

2011 年, 邱勇等 ${ }^{[27]}$ 开发了一种新的辅助配体 2-(1苯基-吡唑-3-基)吡啶, 并以此为基础得到了阳离子铱配 合物 31. 其辅助配体上带有一个县挂式的苯环, 可以显 著增强 LEC 的稳定性. 基于此铱配合物的蓝绿光 LEC 的最大电流效率为 $8.7 \mathrm{~cd} \cdot \mathrm{A}^{-1}$, 亮度为 $37 \mathrm{~cd} \cdot \mathrm{m}^{-2}$. 随后, 他们 ${ }^{[28]}$ 又合成了以吡啶基吡唑为辅助配体, 以苯基吡 唑为环金属配体, 得到了一种新型蓝绿色阳离子铱配合 物 32. 基于此铱配合物的 LEC 具有很好的色纯度, 色坐 标为 $(0.25,0.39)$, 最大电流效率为 $0.1 \mathrm{~cd} \cdot \mathrm{A}^{-1}$.

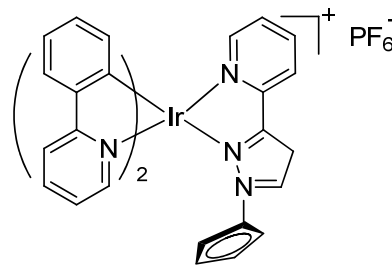

31

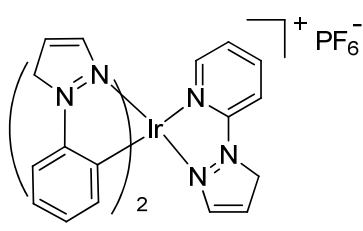

32
陈冰等 ${ }^{[29]}$ 合成了一系列含三唑吡啶的天蓝色和蓝 绿色发光的阳离子铱配合物 33a $\sim 33 \mathrm{~d}$, 其中 33a 和 33c 发天蓝色光, 发射峰在 $458 \mathrm{~nm}$ 处, 33b 和 33d 发蓝绿光, 发射峰在 $484 \mathrm{~nm}$ 处. 铱配合物 33a 和 33b 由于结构中 氰基的存在，基于 $33 \mathrm{a}$ 和 $33 \mathrm{~b}$ 的 LEC 的效率明显较高, 最大电流效率分别为 2.6 和 $6.8 \mathrm{~cd} \cdot \mathrm{A}^{-1}$.<smiles></smiles>

$33 a$

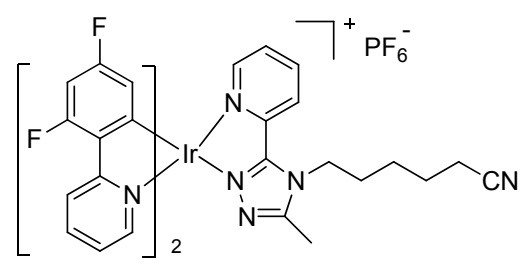

$33 c$

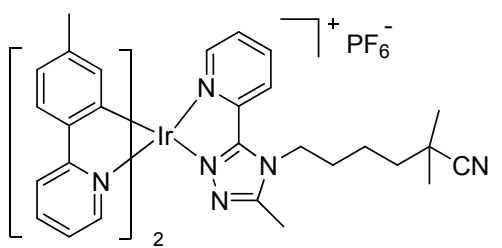

$33 b$<smiles>CC[P+](F)(F)C(C)C</smiles>

$33 d$

2013 年, Tordera 等 ${ }^{[30]}$ 将甲基砜吸电子取代基引入 到 4-苯基吡唑环金属化配体中，合成了 6 种新型的离子 型铱配合物. 吸电子的砜基团的引入可以稳定铱配合物 的最高占据分子轨道(HOMO). 当被用作 LEC 的发光层 时, 均观察到绿色电致发光, 在低驱动电压下均可获得 高效率和高亮度. 其中，配合物 34 的性能最优，其 CIE 
坐标为 $(0.27,0.50)$, 最大亮度为 $890 \mathrm{~cd} \cdot \mathrm{m}^{-2}$, 电流效率 为 $15.5 \mathrm{~cd} \bullet \mathrm{A}^{-1}, \mathrm{EQE}$ 为 $4.9 \%$. 在环金属配体中引入甲基 砜吸电子取代基替代氟取代基, 为未来 LEC 的绿色发 光材料的开辟了新的途径. 随后 Constable 等 ${ }^{[31]}$ 也合成 了一些列砜基修饰的蓝绿光离子型铱配合物 $35 \sim 37$, 它们在固态薄膜下的最大发射波长为分别为 532,535 和 $537 \mathrm{~nm}$, 在溶液中的 PLQY 分别为 74\%, 64\%和 64\%. 由 于配合物上砜基的引入, 配合物 $35 \sim 37$ 的寿命有了大 幅度增长, 分别达到了 $2.33,3.36$ 和 $3.21 \mu \mathrm{s}$.

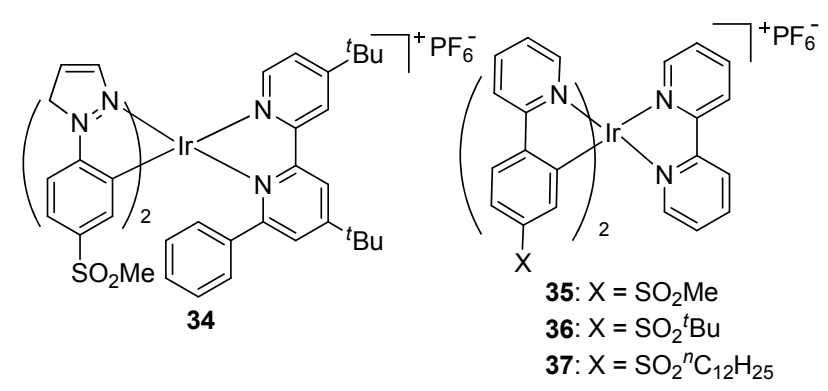

2013 年, Wongkaew 等 ${ }^{[32]}$ 以 2,9-二甲基-1,10-菲咯啉 作为辅助配体, 合成了配合物 38. 以聚乙烯咔唑(PVK) 为主体, 配合物 $\mathbf{3 8}$ 为客体制备了主-客体 LEC. 其最大 发射波长为 $524 \mathrm{~nm}$, 色坐标为 $(0.39,058)$, 最大电流效 率为 $0.55 \mathrm{~cd} \cdot \mathrm{A}^{-1}$, 最大亮度为 $337 \mathrm{~cd} \cdot \mathrm{m}^{-2}$.

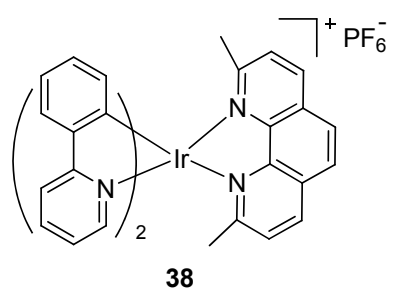

Fernandez-Hernandez 等 ${ }^{[33]}$ 合成了四个以吡啶基三 唑辅助配体的以氟取代的苯基三唑为环金属配体的阳 离子铱配合物. 其中, 基于配合物 39 的 LEC 的最大发 射峰为 $487 \mathrm{~nm}, \mathrm{CIE}$ 坐标为( 0.260 .36$)$, 电流效率为 0.3 $\mathrm{cd} \cdot \mathrm{A}^{-1}$, 最大亮度为 $13 \mathrm{~cd} \cdot \mathrm{m}^{-2}, \mathrm{EQE}$ 为 $0.14 \%$.

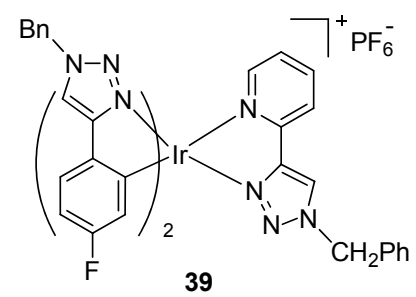

Meier 等 ${ }^{[34]}$ 以 2,6-二氟-2,3-联吡啶作为环金属配体, 以双咪唑卡宾型为辅助配体, 开发了一种新型的深蓝光 离子型铱配合物 40. 在环金属配体上引入空间位阻大
的叔丁基取代基，可以减小分子间的相互作用. 溶液状 态下, 铱配合物 $\mathbf{4 0}$ 的最大发射峰在 $440 \mathrm{~nm}$ 处. 基于配 合物 40 的 $\mathrm{LEC}$ 的最大电流效率为 $5 \mathrm{~cd} \cdot \mathrm{A}^{-1}$, 最大亮度 为 $100 \mathrm{~cd} \cdot \mathrm{m}^{-2}$, 并且具有快速的响应速度 $(17 \mathrm{~s})$, 这是目 前报道的最快的响应时间.

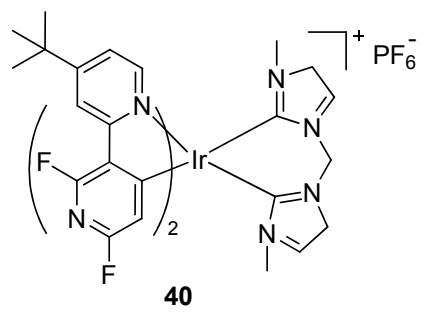

2014 年, Sunesh 等 ${ }^{[35]}$ 以(4-乙基-2-吡啶基)咪唑为辅 助配体和苯基吡啶为环金属配体合成了铱配合物 $\mathbf{4 1}$, 以 2,4-二氟苯基吡啶为环金属配体得到铱配合物 42. 以 铱配合物 41 为发光层的 LEC 的色坐标为 $(0.33,0.56)$, 最 大发射峰为 $522 \mathrm{~nm}$, 最大电流效率为 $1.0 \mathrm{~cd} \cdot \mathrm{A}^{-1}$, 最大 亮度为 $1191 \mathrm{~cd} \cdot \mathrm{m}^{-2}$. 基于铱配合物 $\mathbf{4 2}$ 的 LEC 的最大发 射峰为 $500 \mathrm{~nm}$, 色坐标为 $(0.24,0.44)$, 电流效率为 0.88 $\mathrm{cd} \cdot \mathrm{A}^{-1}$, 最大亮度为 $741 \mathrm{~cd} \cdot \mathrm{m}^{-2}$. 此外, 作者指出咪唑 基辅助配体可以提高铱配合物的 LUMO 能级, 调节离 子型铱配合物的发射移至蓝绿色区域.

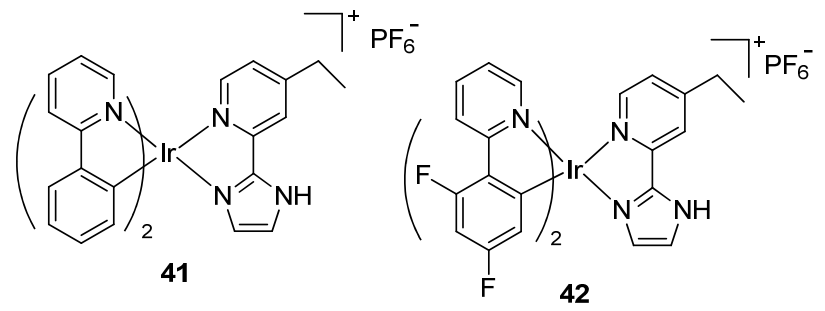

Evariste 等 ${ }^{[36]}$ 用甲氧基取代的 2,3-联吡啶为环金属 配体，4,4-二叔丁基-2,2-联吡啶作为辅助配体开发了一 种新型的离子型铱配合物 43. 溶液状态下, 该铱配合物 的最大发射峰为 $517 \mathrm{~nm}$. 基于配合物 $\mathbf{4 3}$ 的 LEC 的色坐 标为 $(0.33,0.57)$, 最大亮度为 $1054 \mathrm{~cd} \cdot \mathrm{m}^{-2}$, 效率为 9.5 $\mathrm{cd} \cdot \mathrm{A}^{-1}$, EQE 达到 2.8\%. 由于主配体上的甲基取代基, 使得该配合物的发射略微红移.

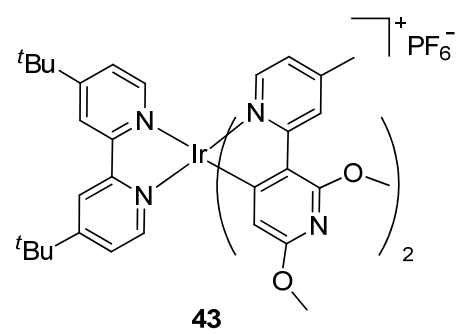

2017 年, Lan 等 ${ }^{[37]}$ 以苯基-5-(2,4,6-三异丙基苯基)- 
1,3,4-噁二唑为环金属配体合成了不含氟的蓝色发光铱 配物 44 和 45 . 在乙腈溶液中, 铱配合物 44 的发射峰为 $505 \mathrm{~nm}$, 铱配合物 45 的发射峰为 468 和 $499 \mathrm{~nm}$. 基于铱 配合物 44 和 45 的 LEC 的最大电流效率分别是 12.4 和 $5.0 \mathrm{~cd} \bullet \mathrm{A}^{-1}$, 最大发射峰分别是 541 和 $505 \mathrm{~nm}$. 和配合物 45 相比, 配合物 44 表现出更快的辐射衰减、更高的发 光效率和更短的激发态寿命. 但是, 配合物 44 和 45 用 于 LEC 中时, 其电致发光光谱比光致发光光谱显示出 较大的红移.

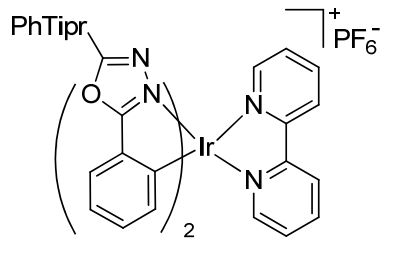

44

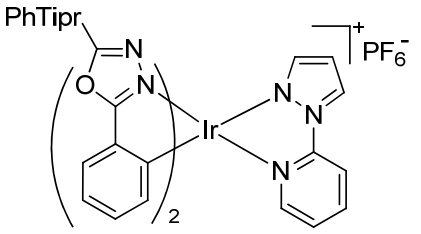

45
2017 年, Namanga 等 ${ }^{[38]}$ 用 2-(4-氟苯基)吡啶为环金 属配体, 用 2,2'-联吡啶、4.4'-二甲基-2,2'-联吡啶、5.5'二甲基-2,2'-联吡啶和 4.4'-二叔丁基-2,2'-联吡啶为辅助 配体研发了一系列离子型铱配合物 $46 \mathrm{a} \sim 46 \mathrm{~d}$. 这些配 合物含有氟取代的环金属化配体和给电子基团(甲基和 叔丁基)取代的二亚胺辅助配体. 配合物 46a 46d 的色 坐标分别为 $(0.43,0.51),(0.38,0.53),(0.36,0.52)$ 和(0.37, $0.54)$; 最大亮度分别为 $1605,1594,1314$ 和 $1193 \mathrm{~cd} \cdot \mathrm{m}^{-2}$; 最大电流效应分别为 $16,15.9,11.3$ 和 $11.9 \mathrm{~cd} \cdot \mathrm{A}^{-1}$. 其中, 配合物 46a 的寿命最高, 达到了 $668 \mathrm{~h}$. 作者发现配合物 中氟的含量对 LEC 性能和稳定性没有直接影响, 但辅 助配体上的给电子取代基会显着降低 LEC 的性能和稳 定性.

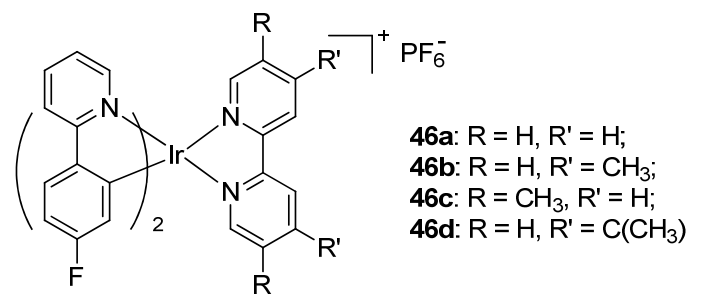

\section{4 应用于白光 LECs 器件的离子型铱配合物的结构} 式

要实现 LEC 的白光发射可以通过混合三基色或两 种互补色(如蓝绿光和红光)来获得. 基于苂光共轭聚合 物的白光 LEC, 一方面容易产生相分离, 另一方面共轭 聚合物的荧光性质限制了 LEC 的发光效率 ${ }^{[39]}$. 与基于 苂光共轭聚合物的白光 LEC 相比, 基于磷光离子型铱 配合物的 LEC 具有以下优点: (1)由于离子型铱配合物 其本身带有对离子, 因而不需要加入电解质; (2)铱配合
物具有磷光特性，其发光效率将超过苂光材料，具有更 简单的结构和更高的效率.

何磊等 ${ }^{[40]}$ 用咪唑衍生物作为辅助配体合成了一系 列新型的阳离子铱配合物 $47 \mathrm{a} \sim \mathbf{4 7 f}$. 与常用的联吡啶类 辅助配体相比, 咪唑类辅助配体可通过醛和胺缩合反应 制得，合成更加简单，咪唑类配体上活泼的 $\mathrm{N}-\mathrm{H}$ 键容 易被其他官能团取代, 分子结构更容易进行化学修饰. 相比于联吡啶类辅助配体，咪唑类辅助配体可以降低配 合物的 LUMO 能级, 使离子型铱配合物的发射光谱蓝 移. 通过调整铱配合物中咪唑类配体的共轭长度, 可以 获得蓝绿光到红光发射. 将这些离子型铱配合物作为发 光层, 得到了蓝光、黄光和橙光 $\mathrm{LEC}$, 其最大效率分别 为 $8.4,18.6$ 和 $13.2 \mathrm{~cd} \cdot \mathrm{A}^{-1}$, 相应的外量子效率分别为 $3.4 \%, 6.0 \%$ 和 $6.1 \%$. 同时，他们把少量红光铱配合物 47e 掺杂到蓝光铱配合物 $47 \mathrm{~b}$ 中, 利用蓝光材料向红光 材料的不完全能量传递, 得到了白光 LEC. 其器件的色 坐标为 $(0.42,0.44)$, 显色指数为 81 . 在 $3.5 \mathrm{~V}$ 电压时, 白 光 LEC 的最大外量子效率为 $5.2 \%$ 、最大电流效率为 11.2 $\mathrm{cd} \cdot \mathrm{A}^{-1}$, 最大功率效率为 $10 \mathrm{~lm} \cdot \mathrm{W}^{-1}$. 由于配合物的紧 密堆积容易导致激发态的自猝灭, 为了克服这个缺陷, 何否等 ${ }^{[41]}$ 在咪唑环上引入了大的取代基团，合成了发 蓝绿光的离子型铱配合物 48. 四苯基甲烷基团具有的 空间位阻可以明显抑制固态下的分子间相互作用和激 发态自猝灭. 通过将少量的红光铱配合物 $47 \mathrm{e}$ 掺杂到铱 配合物 48 中, 得到了白光 LEC. 器件的最大功率效率为 $11.2 \mathrm{~lm} \cdot \mathrm{W}^{-1}$, 色坐标为 $(0.37,0.41)$, 显色指数达到了 80 .
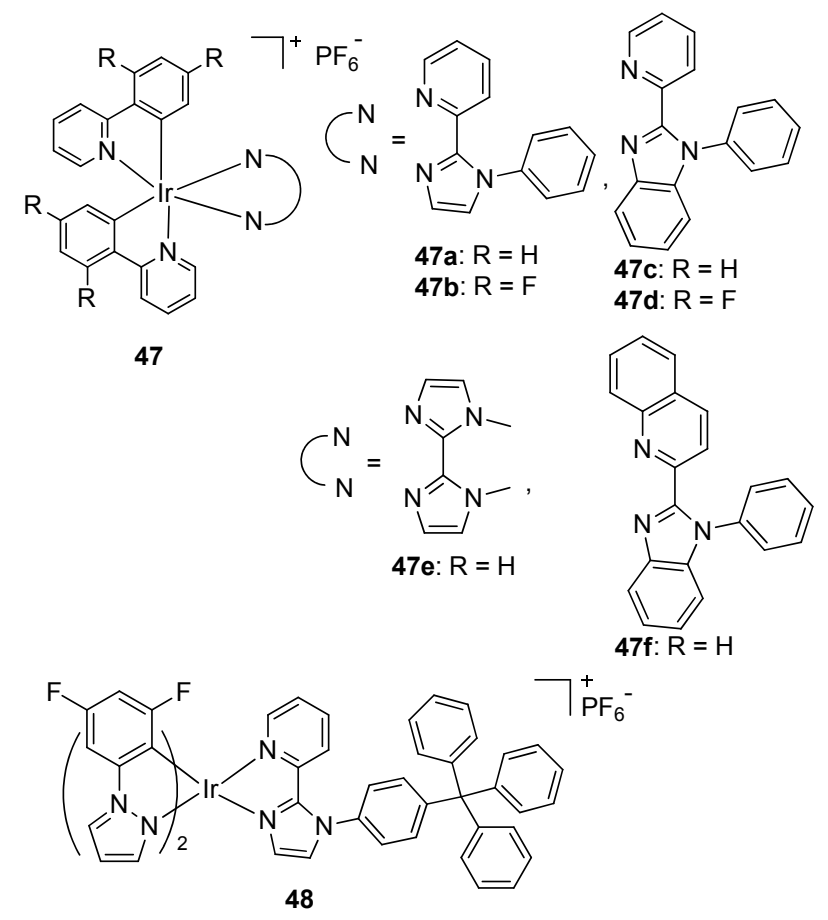

2012 年, $\mathrm{Wu}$ 等 ${ }^{[42]}$ 通过在含有蓝光铱配合物 49 的单 
层 LEC 的玻璃基板的反面加上一个含有红色发光的化 合物 50 的转换层 $(\mathrm{CCL})$, 制造了高效且颜色稳定的白色 发光 LEC. 由于红色发光染料的吸收光谱与发蓝光材料 的发射光谱具有良好的重叠, 因此它们之间可以实现有 效的能量转移, 从而产生有效的红光发射. 采用红光转 换层的白色 LEC 的 EQE 和最大功率效率分别为 $5.93 \%$ 和 $15.34 \mathrm{~lm} \cdot \mathrm{W}^{-1}$, 最大亮度为 $19.79 \mathrm{~cd} \cdot \mathrm{m}^{-2}, \mathrm{CIE}$ 坐标为 $(0.295,0.47)$. 结果表明, 单层蓝光发射 LEC 与红光发射 CCL 相结合, 是制备高效和颜色稳定的白光发光器件 的有效途径之一. $\mathrm{Su}$ 等 ${ }^{[43]}$ 制备了以蓝色发光阳离子铱配 合物 49 作为主体和红色发光的荧光染料配合物 51 作为 客体的高效白色发光电化学电池(LEC). 作者指出, 利 用器件结构的微腔效应可以抑制蓝色磷光配合物的电 致发光光谱中的绿色部分, 因此可以获得更加饱和的蓝 光发射, 当与饱和红色发射结合时, 可以获得 CIE 坐标 接近 $(0.33,0.33)$ 的白光发射. 蓝色磷光敏化红色荧光获 得的 LEC 的最大外量子效率和功率效率分别高达 7.9 和 $15.6 \mathrm{~lm} \bullet \mathrm{W}^{-1}$. 这是当时白光 LEC 报道的最高效率, 表 明了磷光敏化可用于提高白色 LEC 的器件效率.

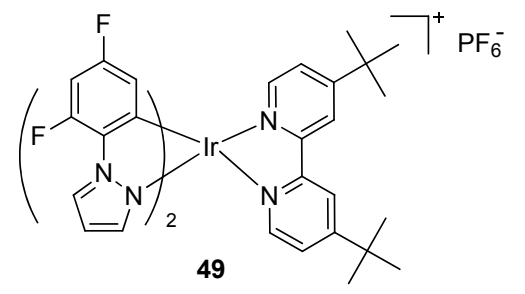<smiles>CC(C)(C)C1=CC(=C(C#N)C#N)C=C(C=Cc2cc3c4c(c2)C(C)(C)CCN4CCC3(C)C)C1</smiles>

50<smiles>O=S(=O)([O-])c1cc(S(=O)(=O)O)ccc1C1=c2cc3c4c(c2Oc2c1cc1c5c2CCCN5CCC1)CCC[N+]=4CCC3</smiles>

2016 年, $\mathrm{Wu}$ 等 ${ }^{[44]}$ 报道了基于阳离子铱配合物的柔 性 LEC. 他们合成了蓝绿光铱配合物 52 和红光铱配合 物 53. 当铱配合物 $\mathbf{5 2}$ 与 $\mathbf{5 3}$ 之间的物质的量之比为 1 : 0.0167 时, 器件的色坐标为 $(0.43,0.42)$, 非常接近纯白 光. 在电压为 $7 \mathrm{~V}$ 时, 器件的最大电流效率为 $9.8 \mathrm{~cd}$ $\mathrm{A}^{-1}$.

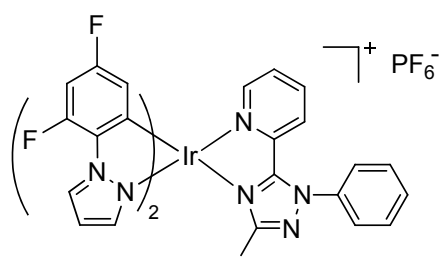

52

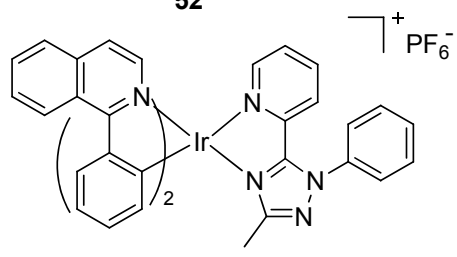

53

2017 年, Nishikitani 等 $^{[45]}$ 将红色磷光铱配合物的 $\mathbf{5 4}$ 作为客体材料，阳离子聚芴 $\mathbf{5 5}$ 作为主体材料，利用主体 材料的蓝光发射和客体材料的红光发射得到了白光发 射. 器件的色坐标为 $(0.28,0.31)$, 显色指数 $(\mathrm{CRI})$ 达到了 95.8 , 最大亮度为 $191 \mathrm{~cd} \cdot \mathrm{m}^{-2}$. 随后, 他们 ${ }^{[46]}$ 又将红色 磷光铱配合物 54 作为客体, 蓝绿色苂光芴和苯并噻二 唑的共聚物 56 作为主体, 并且在发光层中加入固体电 解质聚环氧乙烷(PEO)和 $\mathrm{LiCF}_{3} \mathrm{SO}_{3}$ 制成了主一客体型白 光 LEC. 通过适当调整活性层中各单体的比例，可以有 效调节器件的发光颜色, 器件的 CIE 坐标为 $(0.29,0.34)$, CRI 达到了为 91.5.

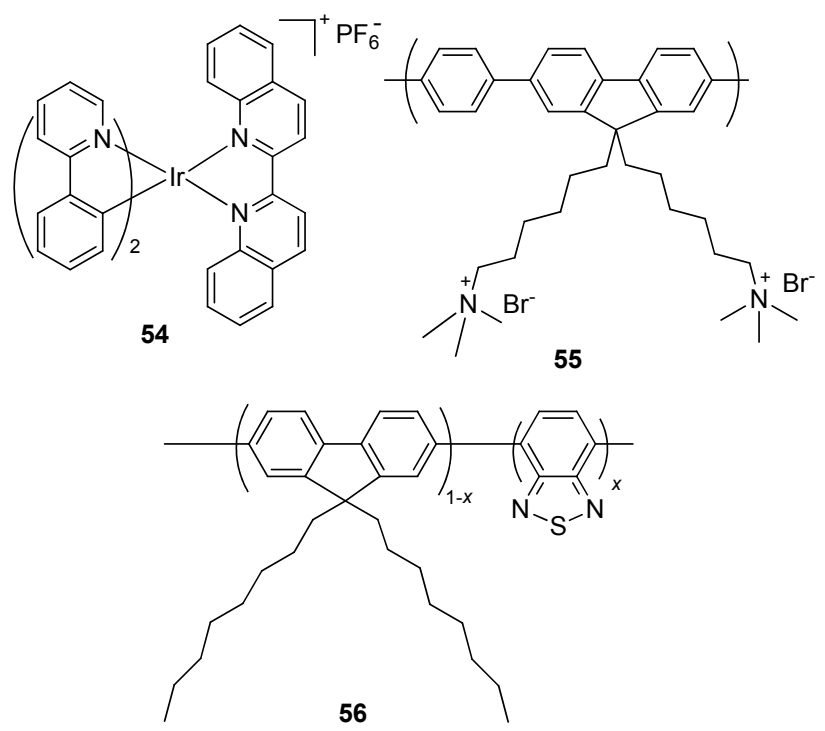

\section{3 中性铱配合物发光电化学池}

中性铱配合物广泛应用于 OLED 中, 并得到了很好 的效果. 因此也有一些科学家尝试把中性铱配合物应用 到 LEC 中. 2006 年, Bolink 等 ${ }^{[47]}$ 在中性的三环金属铱配 合物的外围苯基吡啶配体上引入带电荷的三正丁基膦 基团，使中性铱配合物变为离子型配合物 $\mathbf{5 7}$, 从而实现 
配合物发光颜色的调节. 2009 年, Hong 等 ${ }^{[48]}$ 在中性环金 属铱配合物的辅助配体吡啶甲酸上引入阴离子磺酸基, 其对抗离子为钠离子, 得到离子型配合物 58, 由于钠离 子的半径较小, 和常用的阴离子相比有更快的迁移率, 因此器件的响应时间和稳定性都有明显的提高. 2011 年, Shin 等 ${ }^{[49]}$ 报道了在 OLEDs 中广泛使用的红光材料 59 中掺杂电解质四丁基四氟硼酸铵 $\left(\mathrm{TBABF}_{4}\right)$, 在 $-4 \mathrm{~V}$ 的电压下, 响应时间只需要 $0.8 \mathrm{~s}$, 最大亮度达到了 490 $\mathrm{cd} \cdot \mathrm{m}^{-2}$.

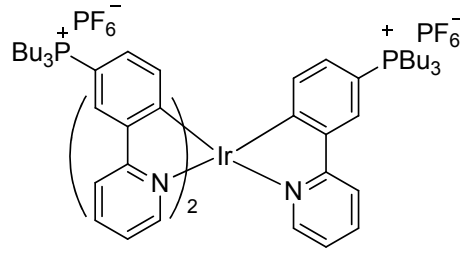

57

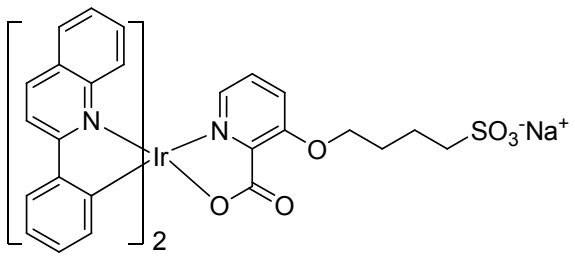

58

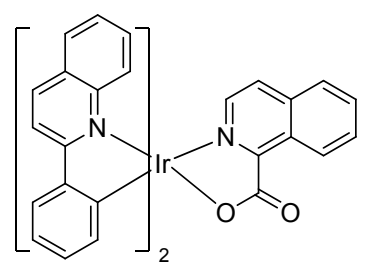

59

\section{4 结论及展望}

基于铱配合物的 LEC 在近几年得到了很大发展, 成为有机电子学领域研究的热点之一. 如今越来越多的 研究者通过修饰配体结构来合成不同颜色 LEC, 开发出 多种新型铱配合物. 然而 LEC 开启时间较长的问题仍 然没有得到很好的解决, 虽然在一些报道中, LEC 的开 启时间缩短至数秒, 但是由于器件稳定性的限制还不能 达到实际应用的要求. 目前, LEC 的效率、亮度和寿命 已经得到了很大提高, 将来要着力于改善器件的稳定性 和缩短启亮时间以及开发出 LEC 效率更高的铱配合物 材料，希望早日实现 LEC 的量产与实际应用.

\section{References}

[1] Gao, F. G.; Bard, A. J. Chem. Mater. 2002, 14, 3465.

[2] Wang, Y. M.; Teng, F.; Hou, Y. B.; Xu, Z.; Wang, Y. S.; Fu, W. F. Appl. Phys. Lett. 2005, 87, 220.

[3] Liu, C. Y.; Bard, A. J. Anal. Chem. 2005, 77, 5339.
[4] Chen, S.-Q.; Da, J.; Zhou, K. F.; Luo, Y. J.; Su, S. J.; Pu, X. M.; Huang, Y.; Lu, Z. Y. Acta Chim. Sinica 2017, 75, 367 (in Chinese). (陈仕琦, 代军, 周凯峰, 罗艳菊, 苏仕健, 蒲雪梅, 黄艳, 卢志 云, 化学学报, 2017, 75, 367.)

[5] Zhou, L.-X.; Liu, S. J.; Zhao, Q.; Ling, Q. D.; Huang, W. Prog. Chem. 2011, 23, 1871 (in Chinese) (周丽霞，刘淑娟，赵强，凌启淡，黄维，化学进展，2011，23， 1871.)

[6] Pei, Q.; Yu, G.; Zhang, C.; Yang, Y.; Heeger, A. J. Science 1995, 269, 1086.

[7] Slinker, J. D.; DeFranco, J. A.; Jaquith, M. J.; Silveira, W. R.; Zhong, Y. W.; Moran-Mirabal, J. M.; Craighead, H. G.; Abruña, H. D.; Marohn, J. A.; Malliaras, G. G. Nat. Med. 2007, 6, 894.

[8] Slinker, J. D.; Gorodetsky, A. A.; Lowry, M. S.; Wang, J.; Parker, S.; Rohl, R.; Bernhard, S.; Malliaras, G. G. J. Am. Chem. Soc. 2004 126, 2763.

[9] Sun, L. F.; Galan, A.; Ladouceur, S.; Slinker, J. D.; ZysmanColman, E. J. Mater. Chem. 2011, 21, 18083.

[10] Chen, H. F.; Wu, C.; Kuo, M. C.; Thompson, M. E.; Wong, K. T. J. Mater. Chem. 2012, 22, 9556.

[11] Zhang, J.; Zhou, L.; Al-Attar, H. A.; Shao, K. Z.; Wang, L.; Zhu, D. X.; Su, Z. M.; Bryce, M. R.; Monkman, A. P. Adv. Funct. Mater. 2013, 23, 4667.

[12] Hu, T.; Duan, L.; Qiao, J.; He, L.; Zhang, D. Q.; Wang, L. D.; Qiu, Y. Synth. Met. 2013, 163, 33.

[13] Ertl, C. D.; Momblona, C.; Pertegás, A.; Junquera-Hernández, J. M.; La-Placa, M. G.; Prescimone, A.; Ortí, E.; Housecroft, C. E.; Constable, E. C.; Bolink, H. J. J. Am. Chem. Soc. 2017, 139, 3237.

[14] Matteucci, E.; Baschieri, A.; Mazzanti, A.; Sambri, L.; Ávila, J.; Pertegás, A.; Bolink, H. J.; Monti, F.; Leoni, E.; Armaroli, N. Inorg. Chem. 2017, 56, 10584.

[15] Martínez-Alonso, M.; Cerdá, J.; Momblona, C.; Pertegás, A.; Junquerahernández, J. M.; Heras, A.; Rodríguez, A. M.; Espino, G.; Bolink, H.; Ortí, E. Inorg. Chem. 2017, 56, 10298.

[16] Namanga, J. E.; Gerlitzki, N.; Mallick, B.; Mudring, A. V. J. Mater. Chem. C. 2017, 5, 3409.

[17] Yeonah, J.; Sunesh, C. D.; Chitumalla, R. K.; Jang, J.; Choe, Y. Org. Electron. 2018, 54, 167.

[18] Xu, W. J.; Liu, S. J.; Ma, T. C.; Zhao, Q.; Pertegás, A.; Tordera, D.; Bolink, H. J.; Ye, S. H.; Liu, X. M.; Sun, S. J. Mater. Chem. 2011, $21,13999$.

[19] Kessler, F.; Costa, R. D.; Di, C. D.; Scopelliti, R.; Ortí, E.; Bolink, H. J.; Meier, S.; Sarfert, W.; Grätzel, M.; Nazeeruddin, M. K. Dalton Trans. 2012, 41, 180.

[20] Sunesh, C. D.; Mathai, G.; Cho, Y. R.; Choe, Y. Polyhedron 2013 $57,77$.

[21] Sunesh, C. D.; Choe, Y. Mater. Chem. Phys. 2015, 156, 206.

[22] Zeng, Q.-Y.; Li, F. S.; Guo, T. L.; Shan, G. G.; Su, Z. M. Sci. Rep. 2016, 6, 27613.

[23] Jeon, Y.; Sunesh, C. D.; Chitumalla, R. K.; Jang, J.; Choe, Y. Electrochim. Acta 2016, 195, 112

[24] Jo, S.; Choe, Y. S. Mol. Cryst. Liq. Cryst. 2017, 654, 221.

[25] Mydlak, M.; Bizzarri, C.; Hartmann, D.; Sarfert, W.; Schmid, Günter; Cola, L. D. Adv. Funct. Mater. 2010, 20, 1812.

[26] Yang, C. H.; Beltran, J.; Lemaur, V.; Cornil, J.; Hartmann, D.; Sarfert, W.; Fröhlich, R.; Bizzarri, C.; Cola, L. D. Inorg. Chem. 2010, 49, 9891.

[27] He, L.; Duan, L.; Qiao, J.; Zhang, D. Q.; Wang, L. D.; Qiu, Y. Chem. Commun. 2011, 47, 6467.

[28] Hu, T.; Duan, L.; Qiao, J.; He, L.; Zhang, D.; Wang, R.; Wang, L.; Qiu, Y. Org. Electron. 2012, 13, 1948.

[29] Chen, B.; Li, Y.; Yang, W.; Luo, W.; Wu, H. Org. Electron. 2011, 12,766 .

[30] Tordera, D.; Constable, E. C.; Zampese, J. A.; Housecroft, C. E.; Bolink, H. J. Chem.-Eur. J. 2013, 19, 8597.

[31] Constable, E. C.; Ertl, C. D.; Housecroft, C. E.; Zampese, J. A. Dalton. Trans. 2014, 43, 5343.

[32] Wongkaew, P.; Mahanitipong, U.; Wongsang, N.; Sahasithiwat, S.; 
Jitchati, R. e-J. Surf. Sci. Nanotechnol. 2014, 12, 141.

[33] Fernández-Hernández, J. M.; Ladouceur, S.; Shen, Y.; Iordache, A.; Wang, X.; Donato, L.; Gallagherduval, S.; Villa, M. D. A.; Slinker, J. D.; Cola, L. D. J. Mater. Chem. C 2013, 1, 7440.

[34] Meier, S. B.; Sarfert, W.; Junquera-Hernandez, J. M.; Delgado, M.; Tordera, D.; Orti, E.; Bolink, H. J.; Kessler, F.; Scopelliti, R.; Graetzel, M.; Nazeeruddin, M. K.; Baranoff, E. J. Mater. Chem. C 2013, 1,58 .

[35] Sunesh, C. D.; Mathai, G.; Choe, Y. Org. Electron. 2014, 15, 667.

[36] Evariste, S.; Sandroni, M.; Rees, T.; Roldancarmona, C.; Gilescrig, L.; Bolink, H.; Baranoff, E.; Zysmancolman, E. J. Mater. Chem. C 2014, 2, 5793

[37] Lan, Y.; Li, G.; Zhen, W.; He, Y.; Liu, Y.; He, L. Dyes Pigm. 2017, $144,158$.

[38] Namanga, J. E.; Gerlitzki, N.; Mudring, A. V. Adv. Funct. Mater. 2017, 27, 1605588.

[39] Yang, Y.; Pei, Q. J. Appl. Phys. 1997, 81, 3294.

[40] He, L.; Qiao, J.; Duan, L.; Dong, G.; Zhang, D.; Wang, L.; Qiu, Y. Adv. Funct. Mater. 2009, 19, 2950.
[41] He, L.; Duan, L.; Qiao, J.; Dong, G.; Wang, L.; Qiu, Y. Chem. Mater. 2010, 22, 3535 .

[42] Wu, H. B.; Chen, H. F.; Liao, C. T.; Su, H. C.; Wong, K. T. Org. Electron. 2012, 13, 483.

[43] Su, H. C.; Chen, H. F.; Chen, P. H.; Lin, S. W.; Liao, C. T.; Wong, K. T. J. Mater. Chem. 2012, 22, 22998.

[44] Wu, J.; Li, F.; Zeng, Q.; Nie, C.; Ooi, P. C.; Guo, T.; Shan, G.; Su, Z. Org. Electron. 2016, 28, 314.

[45] Nishikitani, Y.; Suga, K.; Uchida, S.; Nishimura, S.; Oyaizu, K.; Nishide, H. Org. Electron. 2017, 51, 168.

[46] Nishikitani, Y.; Cho, T.; Uchida, S.; Nishimura, S.; Oyaizu, K.; Nishide, H. ChemPlusChem 2018, 83, 463.

[47] Bolink, H. J.; Cappelli, L.; Coronado, E.; Grätzel, M.; Ortí, E.; Costa, R. D.; Viruela, P. M.; Nazeeruddin, M. K. J. Am. Chem. Soc. 2006, 128, 14786.

[48] Kwon, T. H.; Yong, H. O.; Shin, I. S.; Hong, J. I. Adv. Funct. Mater. 2009, 19, 711.

[49] Shin, I. S.; Lim, H. C.; Oh, J. W.; Lee, J. K.; Kim, T. H.; Kim, H. Electrochem. Commun. 2011, 13, 64. 